
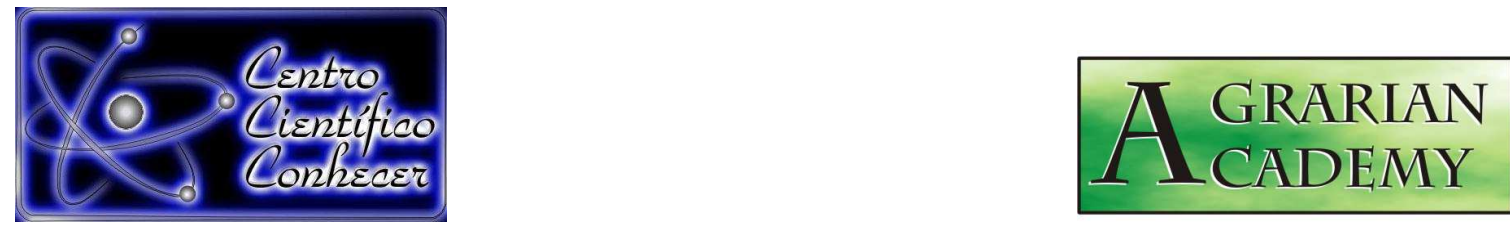

\title{
INFLUÊNCIA DA COMPACTAÇÃO DO SOLO NO DESENVOLVIMENTO DO SISTEMA RADICULAR DO FEIJÃO (Phaseolus vulgaris L.)
}

\author{
Lorena Lima Ferraz¹, Amanda Coqueiro Silva1, Letícia Vitória Fernandes Rocha1, \\ Thereza Magalhães Simões de Oliveira ${ }^{1}$ Joseane Oliveira da Silva² \\ ${ }^{1}$ Federal Institute of Education, Science and Technology of Bahia, City of Vitória da \\ Conquista. Member of Tutorial Education Program. \\ 2 Professor Dr. of the Coordination of Environmental Engineering, Federal Institute of \\ Education, Science and Technology, Vitória da Conquista/Brazil. \\ lorenalferraz@gmail.com
}

Recebido em: 30/11/2017 - Aprovado em: 15/12/2017 - Publicado em: 31/12/2017 DOI: 10.18677/Agrarian_Academy_2017b17

\begin{abstract}
A presente pesquisa reverbera o efeito da compactação do solo no desenvolvimento da cultura do feijão Phaseolus vulgaris $L$. A pesquisa analisou a compactação do latossolo vermelho amarelo em recipientes, averiguou as características físicas do solo e posteriormente comparou o desenvolvimento do feijoeiro entre o solo sem compactação e o solo com maior redução do volume de lacunas, de maior coesão, resistência e diminuição da permeabilidade. A metodologia utilizada submeteu o latossolo vermelho amarelo distrófico à compactação por densidade. Com isso, a partir da redução dos macroporos pelo efeito da compactação, o resultado foi prejudicial à penetração radicular e hídrica, ocasionando um crescimento vegetal diminuto.
\end{abstract}

PALAVRAS-CHAVE: Compactação; feijão, Física do solo, solo. 


\title{
INFLUENCE OF SOIL COMPACTION IN THE DEVELOPMENT OF THE BEAN RADICAL SYSTEM (Phaseolus vulgaris L.)
}

\begin{abstract}
This research has reverberated the effect of soil compaction on the development of the bean crop Phaseolus vulgaris $L$. The research analyzed the compaction of the yellow red latosol in containers, ascertained the physical characteristics of the soil and later compared the development of the bean between the soil without compaction and the soil with greater reduction of the volume of gaps, of greater cohesion, resistance and decrease of the permeability. The methodology used submitted the dystrophic yellow red latosol to density compaction. Thus, from the reduction of the macropores, by the effect of compaction, a damaging result to the radicular and water penetration, causing a small plant growth.
\end{abstract}

KEYWORDS: Soil physics; compaction; soil; bean.

\section{INTRODUÇÃO}

Um dos objetivos das pesquisas em física do solo é estabelecer a relação quantitativa entre produção das culturas e compactação do solo (GUBIANI, 2013). O sucesso do estabelecimento de uma cultura depende do ambiente do solo que, inicialmente, deve ser adequado à germinação da semente e desenvolvimento da planta (MODOLO et al., 2011). Por conseguinte, a análise do solo juntamente com o manejo adequado se mostra de grande valia para prevenir o inexpressivo crescimento da cultura.

Duas propriedades físicas mais importantes referem-se à textura do solo, que segundo Crispim (2012) é definida como a distribuição granulométrica das partículas de areia, silte e argila, e a estrutura do solo define-se como o padrão de arranjamento e organização das partículas primárias do solo para formar agregados (SILVA, 2013). Fragmentos grosseiros característicos de solos arenosos reduzem o volume disponível de solo para retenção de água e crescimento de raízes, entretanto, em solos densos, os espaços entre fragmentos podem fornecer caminhos para drenagem de água e crescimento de raízes (VAN LIER, 2010), caracterizada como microporosidade, resultante da atuação de substâncias cimentantes que estabilizam os agregados afetando diretamente a capacidade de retenção de água pelo solo (SILVA, 2013).

A porosidade, de acordo com Teixeira et al., (2009), é uma propriedade física definida pela relação entre o volume de poros e o volume total de um certo material, ou seja, a porosidade é a quantidade de espaços vazios de um determinado solo, onde a água ocupa uma parte destes espaços, sendo as lacunas restantes ocupadas pelo ar (RAIJ, 1981). Esta propriedade interfere na aeração, condução e retenção de água, resistência à penetração e à ramificação das raízes no solo e, consequentemente, no aproveitamento de água e nutrientes disponíveis (TOGNON, 1991). De acordo com Hillel (1980), o solo ideal deve apresentar um volume e dimensão dos poros adequados 
para a entrada, movimento e retenção de água e ar para atender às necessidades das culturas (RIBEIRO et al., 2007).

A densidade do solo é diretamente ligada e afetada pela porosidade. Define-se como a massa por unidade de volume de solo seco e este volume inclui partículas sólidas e espaço poroso do solo (VAN LIER, 2010). É sabido então, que qualquer alteração na densidade do solo irá afetar diretamente a quantidade de espaços vazios presentes, podendo ocasionar inúmeras alterações que acometeriam a qualidade do solo e por consequência os seres que o usufruem (VAN LIER, 2010).

Algumas práticas de manejo provocam o aumento na densidade do solo, o que implica em diminuição da aptidão do solo para crescimento radicular, provocando também redução da aeração e mudanças indesejáveis no comportamento da água no solo, como redução na infiltração (VAN LIER, 2010). Segundo Mantovani (1987), os problemas da técnica de compactação do solo têm sido uma preocupação por parte dos agricultores e, coincidentemente, tais problemas começam a chamar atenção nas áreas onde a prioridade dos trabalhos com máquinas e implementos se restringe a produção e a qualidade do trabalho com o solo, como no cultivo de grãos, ou seja, o manejo adequado do solo tem sido considerado como secundário.

O feijão (Phaseolus vulgaris L.) é produzido e encontrado em todos os seus tipos, estando presente em todas as regiões do Brasil, que segundo a Food and Agriculture Organization of the United Nations (2011) é o líder em aproveitamento, atingindo a produção total de 3.296.411 toneladas e produtividade média de $1066 \mathrm{~kg} / \mathrm{ha}$ em 2016 (IBGE, 2016). O feijão carioca é o tipo de feijão mais consumido (63\%) pelos brasileiros, estando à frente do feijão de corda (19\%) e do feijão de grão preto $(18 \%)$ (DEPEC, 2017).

Devido a todos esses dados, a escolha do manejo correto para o bom desenvolvimento do feijoeiro é fundamental para que os índices de produção sejam mantidos, e para tal, é necessária a expansão das pesquisas relacionadas ao crescimento e produção do grão. O objetivo desta pesquisa foi analisar a relação entre a compactação e o crescimento radicular do feijoeiro e como este interfere no desenvolvimento de toda a planta, analisando fatores que vão desde área foliar até a massa total do vegetal.

\section{MATERIAL E MÉTODOS}

O experimento foi conduzido na casa de vegetação do Instituto Federal de Educação, Ciência e Tecnologia da Bahia, campus Vitória da Conquista, situada a 1453'; de latitude sul, 4048'; de longitude oeste e $870 \mathrm{~m}$ de altitude, no período de abril a junho de 2016. O solo utilizado foi o latossolo vermelho amarelo distrófico, típico, textura franco argilo arenosa, relevo plano e coletado na camada de 0 a 0,2 $\mathrm{m}$, o qual foi destorroado, peneirado e colocados em vasos com capacidade para um $\mathrm{kg}$ de solo.

O delineamento experimental utilizado foi o Inteiramente Casualizado (DIC), composto por quatro tratamentos $\left(1 ; 1,2 ; 1,26\right.$ e $\left.1,33 \mathrm{~g} / \mathrm{cm}^{3}\right)$ em três repetições, totalizando 12 unidades experimentais. A semente utilizada foi do feijão carioca tipo 1 , 
quatro foram colocadas para germinação, permanecendo após somente uma por recipiente.

O processo de compactação seguiu a metodologia proposta por Azevedo (1996), submetendo o solo à compactação a uma determinada massa superior à capacidade do recipiente, o que ocasiona a redução de espaços vazios no solo, resultando na compactação por densidade. A irrigação foi feita utilizando água no volume estabelecido por fase da cultura, variando de 300 a 400 mm de lâmina de água para cada vaso.

Após o desbaste, foi feita a colheita das plantas separando em parte aérea (folhas, caule e vagens) e raiz, e posteriormente determinou-se a massa fresca através da balança de laboratório. Foi determinada a área foliar total para cada parcela através da análise de imagem digital (scanner) utilizando o software Winfolia @ (figura 1). $O$ aparelho consta de uma prancheta e um pequeno scanner acoplado a um microcomputador, fornecendo os valores de área diretamente ao inserir a folha no equipamento. Posteriormente, o material vegetal foi acondicionado em sacos de papel e levados para a estufa a 65 $\mathrm{C}$ até peso constante para determinação da massa seca.

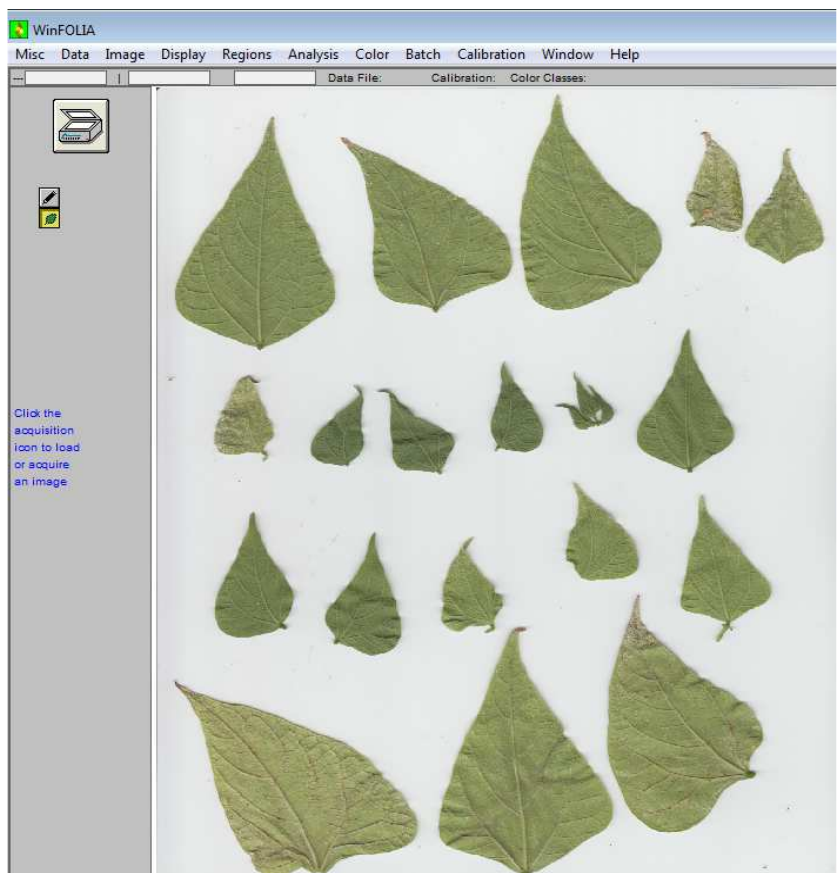

FIGURA 1. Interface do Software de monitoramento foliar Winfolia ${ }^{\circledR}$. Fonte: Autores (2016)

\section{RESULTADOS E DISCUSSÃO}

A partir da análise dos dados obtidos e apresentados na Tabela 1, a compactação do solo influenciou em todas as variáveis analisadas da planta. 
TABELA 1. Valores da massa seca das variáveis folha, caule, vagens, parte aérea, raíz e massa seca total

\begin{tabular}{cccccccc}
\hline \multirow{2}{*}{$\begin{array}{c}\text { Tratamento } \\
\left(\mathrm{g} / \mathrm{cm}^{3}\right)\end{array}$} & Repetição & \multicolumn{7}{c}{ Massa seca $(\mathrm{g})$} \\
\cline { 2 - 8 } & & Folha & Caule & Vagens & Parte aérea & Raíz & Massa seca total \\
\hline 1 & 1 & 3,67 & 2,2 & 1,02 & 6,89 & 12,68 & 19,57 \\
1 & 2 & 3,53 & 1,9 & 3,78 & 9,21 & 14,67 & 23,88 \\
1 & 3 & 5,45 & 1,77 & 1,37 & 8,59 & 12,37 & 20,96 \\
\hline 1,2 & 1 & 3,5 & 1,72 & 0,31 & 5,53 & 10,27 & 15,8 \\
1,2 & 2 & 5,1 & 1,91 & 0,04 & 7,05 & 6,59 & 13,64 \\
1,2 & 3 & 4,1 & 1,51 & 0,38 & 5,99 & 7,08 & 13,07 \\
\hline 1,266 & 1 & 4,18 & 1,35 & 0,41 & 5,94 & 10,4 & 16,34 \\
1,266 & 2 & 5,7 & 1,6 & 0,16 & 7,46 & 13,4 & 20,86 \\
1,266 & 3 & 3,7 & 1,81 & 1,2 & 6,71 & 11,05 & 17,76 \\
\hline 1,33 & 1 & 2,72 & 1,32 & 0,95 & 4,99 & 15 & 19,99 \\
1,33 & 2 & 2,93 & 1,36 & 1,03 & 5,32 & 7,04 & 12,36 \\
1,33 & 3 & 3,47 & 1,6 & 0,79 & 5,86 & 4,95 & 10,81 \\
\hline
\end{tabular}

Embora a elevação da densidade do solo tenha afetado todas as partes analisadas, esse aumento causou redução mais considerável no valor da variável Vagem, apresentando um decaimento de $55,34 \%$ do maior nível de compactação em relação ao tratamento controle. A Tabela 2 mostra os valores médios da massa seca dos quatro tratamentos colocados em experimentação.

TABELA 2. Valores médios da massa seca das variáveis folha, caule, vagens, parte aérea, raíz e massa seca total.

\begin{tabular}{ccccccc}
\hline $\begin{array}{c}\text { Tratamento } \\
\left(\mathrm{g} / \mathrm{cm}^{3}\right)\end{array}$ & \multicolumn{5}{c}{ Massa seca $(\mathrm{g})$} \\
\cline { 2 - 7 } & Folha & Caule & Vagens & Parte aérea & Raíz & Massa seca total \\
\hline 1,2 & 4,22 & 1,96 & 2,06 & 8,23 & 13,24 & 21,47 \\
1,266 & 4,23 & 1,71 & 0,24 & 6,19 & 7,98 & 14,17 \\
1,33 & 3,04 & 1,59 & 0,59 & 6,70 & 11,62 & 18,32 \\
\hline
\end{tabular}

Tais valores são alcançados pela relação da densidade do solo com o desenvolvimento total do feijão. Para este estudo, à medida que a compactação do solo aumenta, a quantidade de macroporos é consideravelmente reduzida, afetando a penetração das raízes e a condutividade hidráulica, e, como consequência, o crescimento do vegetal é limitado. Após aplicação do modelo de regressão linear (figura 2), evidenciou-se a boa aplicabilidade ao experimento. 

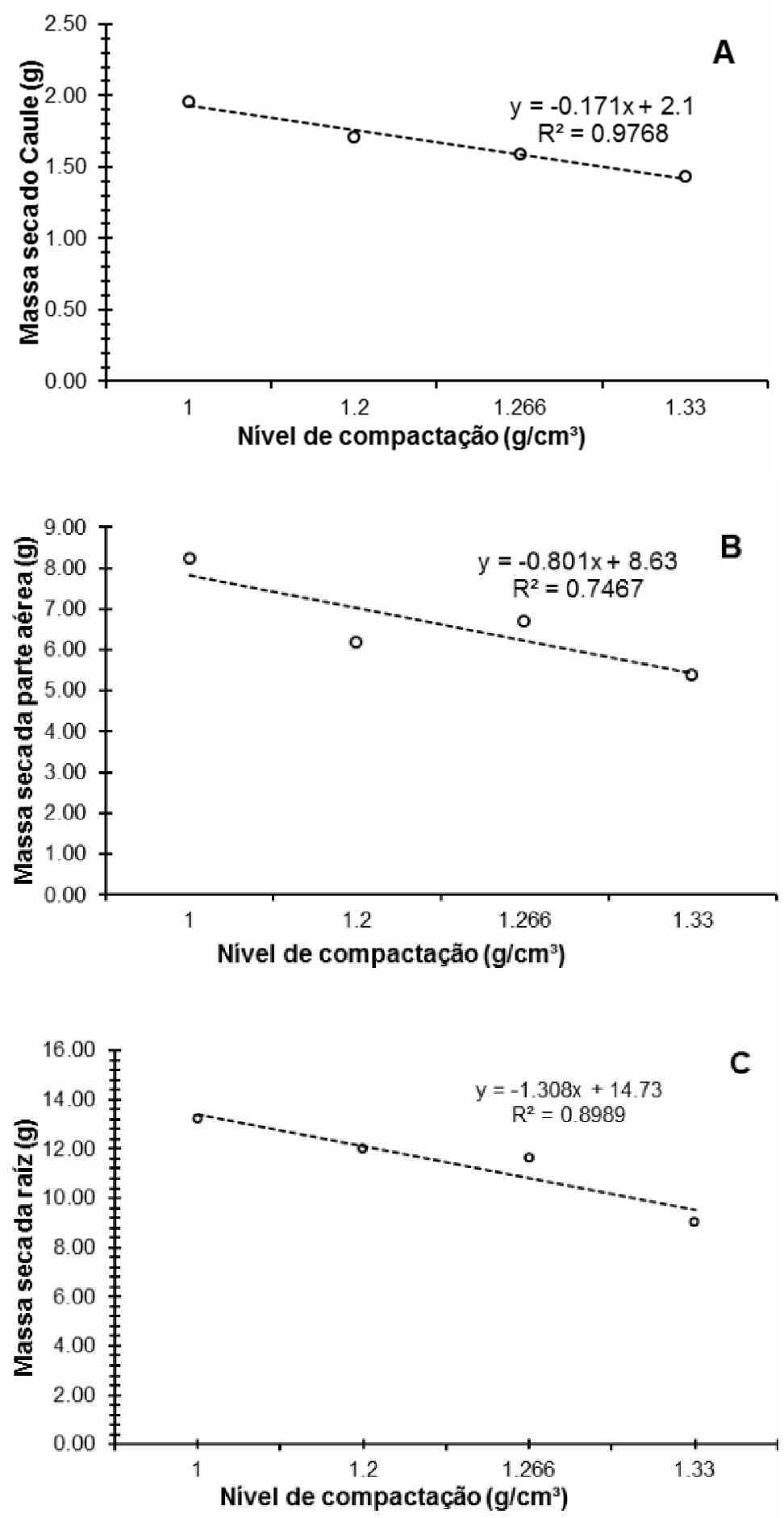

FIGURA 2. Caule (A), parte aérea (B) e raízes (C) das plantas do Phaseolus vulgaris L.

AGRARIAN ACADEMY, Centro Científico Conhecer - Goiânia, v.4, n.8; p. 1712017 
A redução linear não significativa entre os tratamentos testados na variável caule pode se associar ao curto período em que o experimento foi conduzido, o que torna o efeito da compactação pouco evidente em relação às outras variáveis de estudo.

A queda do valor da massa seca da raíz do feijoeiro submetido ao maior nível de compactação foi de $32 \%$ em relação ao tratamento controle. Foi exposto por Pereira Junior et al. (2012), após observarem o crescimento de Moringa oleifera em solo compactado, que as condições de compactação do solo também prejudicaram significativamente o crescimento radicular. A Tabela 3 apresenta os valores de área foliar das plantas cultivadas em diferentes densidades.

TABELA 3. Valores médios da quantidade de folhas e área foliar de cada tratamento.

\begin{tabular}{ccc}
\hline Tratamento $\left(\mathrm{g} / \mathrm{cm}^{3}\right)$ & $\begin{array}{c}\text { Quantidade média de } \\
\text { folhas }\end{array}$ & Área Foliar Total $\left(\mathrm{cm}^{2}\right)$ \\
\hline 1 & 48 & 232,423 \\
1,2 & 65 & 292,008 \\
1,266 & 50 & 215,853 \\
1,33 & 53 & 210,125 \\
\hline
\end{tabular}

A redução na área foliar total do tratamento de maior densidade em relação ao tratamento base não apresentou diferenças significativas. Esse fato é justificado pelo maior número de folhas nos tratamentos de crescentes densidades, entretanto, em pequenos valores de área. Já o tratamento controle possuiu uma quantidade reduzida de folhas com maiores tamanhos.

Santos (2017), afirma que a análise da variável área foliar se mostra de grande importância visto que os resultados obtidos fazem desse um importante parâmetro a ser considerado na hora do estudo da planta a ser instalada em solo compactado, o que afeta diretamente a produtividade. Já Gubiani (2014) certifica que a compactação do solo limita o acesso de água pelas plantas e intensifica o estresse hídrico, assim, parte dessas perdas está sendo causada pela compactação do solo, fator que interfere diretamente na área foliar por favorecer a perda por evapotranspiração e não sendo compensado por absorção, limitando o seu crescimento aéreo.

\section{CONCLUSÃO}

A compactação do solo, ao reduzir consideravelmente a quantidade de macroporos, influenciou na redução do valor da massa das variáveis: folha, caule, vagens, raiz e área foliar do feijoeiro.

Os valores de massa seca do caule e área foliar apresentaram redução pouco significativa. O conhecimento do comportamento dos parâmetros analisados sob níveis de compactação é de fundamental importância no estabelecimento da cultura estudada em solo de elevada densidade. 


\section{REFERÊNCIAS}

AZEVEDO, A. S.; KANWAR, R. S.; SINGH, P.; PEREIRA, L. S. Movement of NO3 and atrazine through soil columns as affected by lime application. Transactions of the Asae, St. Joseph, v.39, n.3, p.937-945, 1996.

CRISPIM, F. A. Textura e Estrutura dos solos. 2012. Disponível em:<http://sinop.unemat.br/site_antigo/prof/foto_p_downloads/fot_400903_textuua_e_e stuutuua_pdf.pdf>. Acesso em: 24 abr. 2017.

DEPEC. Feijão, janeiro de 2017. Departamento de pesquisas e estudos econômicos. Disponível em: <https://www.economiaemdia.com.br/EconomiaEmDia/pdf/infset_feijao.pdf>. Acesso em: 18 mar. 2017.

GUBIANI, P. I.; REICHERT, J.M.; REINERT, D. J. Indicadores hídrico-mecânicos de compactação do solo e crescimento de plantas. Revista Brasileira de Ciência do Solo, v.37, p. 1-10, 2013. Disponível em: <http://dx.doi.org/10.1590/S010006832013000100001>. doi: 10.1590/S0100-06832013000100001

GUBIANI, P. I.; REICHERT, J.M.; REINERT, D. J. Interação entre disponibilidade de água e compactação do solo no crescimento e na produção do feijoeiro. Revista Brasileira de Ciência do Solo, v. 38, p. 765-773, 2014. Disponível em: <http://dx.doi.org/10.1590/S0100-06832014000300008>. doi: 10.1590/S010006832014000300008

HILLEL, D. Fundamentals of soil physics. New York: Academic, 1980. 413 p.

IBGE. Indicadores IBGE, Estatística da Produção Agrícola 2016. Disponível em: <ftp://ftp.ibge.gov.br/Producao_Agricola/Fasciculo_Indicadores_IBGE/estProdAgr_2016 01.pdf>. Acesso em: 18 mar. 2017.

MANTOVANI, E. C. Compactação do solo. Informativo Agropecuário. Belo Horizonte, v. 13, n. 147,1987 .

MODOLO, A. J.; TROGELLO, E.; NUNES, A. L.; SILVEIRA, J. C. M.; KOLLING, E. M.; Efeito da compactação do solo sobre a semente no desenvolvimento da cultura do feijão. Acta Scientiarum: Agronomy, v.331, p. 89-95, 2011. Disponível em: <http://dx.doi.org/10.4025/actasciagron.v33i1.4236>. 10.4025/actasciagron.v33i1.4236.

PEREIRA JUNIOR, E. B.; NUNES, E. M.; SOUTO, J. S.; AGUIAR NETO, P. ROLIM, H. O. Avaliação do crescimento de raízes e parte aérea da morinqueira (Moringa oleifera) 
sob condições de solo compactado. Revista verde de Agroecologia e Desenvolvimento sustentável. v. 7, n.2, p.96-101, 2012.

RAIJ, B. V. Avaliação da Fertilidade do Solo. 2. ed. SP. Piracicaba: Instituto de Potassio e Fosfato. 1981.

RIBEIRO, K. D.; MENEZES, S. M.; MESQUITA, M. G. B. F.; SAMPAIO, F. M. T. Propriedades Físicas do Solo Influenciadas pela Distribuição de Poros de Seis Classes de Solos da Região de Lavras-MG. Ciências e Agrotecnologia., Lavras, v. 31, n. 4, p. 1167-1175, 2007. Disponível em:< http://dx.doi.org/10.1590/S141370542007000400033>. doi: 10.1590/S1413-70542007000400033.

SANTOS, D. N.; SILVA, T. S. S.; BARBOSA, A. L. P; SANTOS, C. G. FONSECA, C. S.; BRANDÃO, L. J. A. V. Efeito da compactação do solo na área foliar de plantas de Crotalaria juncea I. e Crotalaria spectabilis roth. In: Anais da III reunião nordestina de Ciência do Solo. Ciência do Solo: Integração e uso do conhecimento para uma agricultura sustentável no Nordeste. Aracajú, 2017.

SILVA, A. P. Estrutura do solo - Atributos físicos e químicos do solo. 2013. Disponível $\quad$ em:< www.ccta.ufcg.edu.br/admin.files.action.php?action=download\&id=1842>. Acesso em: 24 abr. 2017.

TEIXEIRA, W.; FAIRCHILD, T. R.; TOLEDO, M. C. M.; TAIOLI, F. Decifrando a Terra. 2 ed. Companhia Editora Nacional. São Paulo. 2009.

TOGNON, A. A. Propriedades físico-hídricas do Latossolo Roxo da região de Guairá-SP sob diferentes sistemas de cultivo. 1991. 85 f. Dissertação (Mestrado) Escola Superior de Agricultura de Luiz de Queiroz, Piracicaba, 1991.

VAN LIER, Q. J. Física do solo. 1. ed. Viçosa: Sociedade Brasileira de Ciência do solo, 2010. 